\title{
Anti-Colorectal Cancer Chemotherapy-Induced Diarrhoea: Current Treatments and Side-Effects
}

\author{
Rachel M. McQuade', Joel C. Bornstein ${ }^{2}$, Kulmira Nurgali ${ }^{*}$ \\ ${ }^{1}$ College of Health and Biomedicine, Victoria University, Melbourne, Australia \\ ${ }^{2}$ Department of Physiology, Melbourne University, Melbourne, Australia \\ Email: ${ }^{*}$ Kulmira.Nurgali@vu.edu.au
}

Received 8 January 2014; revised 7 February 2014; accepted 6 March 2014

Copyright (C) 2014 by authors and Scientific Research Publishing Inc.

This work is licensed under the Creative Commons Attribution International License (CC BY). http://creativecommons.org/licenses/by/4.0/

(c) (i) Open Access

\begin{abstract}
Chemotherapy-induced diarrhoea (CID) is a common side-effect experienced by patients being treated with a variety of antineoplastic agents. Approximately $80 \%$ of patients undergoing chemotherapeutic treatment for colorectal and other gastrointestinal cancers present with CID; moreover, about $5 \%$ of early deaths associated with combination anti-cancer chemotherapy are due to CID. Chronic post-treatment diarrhoea amongst cancer survivors can persist for more than 10 years greatly effecting long-term quality of life. Gastrointestinal toxicities such as diarrhoea and vomiting are amongst the primary contributors to dose reductions and delays throughout anti-cancer treatment, presenting a significant hurdle in clinical management of anti-cancer regimes and often result in sub-optimum treatment. However, little is known about pathophysiological mechanisms underlying CID. This work provides a review of chemotherapy-induced diarrhoea, current management guidelines, and shortcomings of current treatments as well as emerging and already existing anti-diarrhoeal treatments potentially suitable for CID.
\end{abstract}

\section{Keywords}

Oxaliplatin; Irinotecan, 5-Fluorouracil, Cisplatin, Carboplatin, Chemotherapy, Colorectal Cancer, Chemotherapy-Induced Diarrhoea

\section{Introduction}

Colorectal cancer (CRC) is the second leading cause of cancer-related mortality in the western world [1] [2].

\footnotetext{
"Corresponding author.
}

How to cite this paper: McQuade, R.M., et al. (2014) Anti-Colorectal Cancer Chemotherapy-Induced Diarrhoea: Current Treatments and Side-Effects. International Journal of Clinical Medicine, 5, 393-406. 
With global incidence and mortality rates of approximately 1.2 million and 610,000 respectively per year [3], and consequently low 5 and 10 year survival rates, CRC is projected to account for more than 1.6 million deaths annually by 2020 [4], placing it amongst the highest contributors to cancer related deaths globally [3] [5]-[7].

Surgical resection of the tumour-bearing and adjacent segments of intestines is used in an attempt to eliminate all cancer cells. However, about half of patients are diagnosed beyond stage III, where penetration of the intestinal wall and metastasis to surrounding tissues have already occurred; therefore, chemotherapeutic intervention has been implemented as a mainstream adjuvant therapy, broadening the avenues of treatment [7] [8].

Advances in medicine over the last 50 years have widened the prospects of CRC treatment allowing it to be approached and administered in a variety of ways. Surgical resection, radiotherapy and/or chemotherapy depending on the location of tumour may now be combined and tailored for targeted treatment. Furthermore, chemotherapeutics may be manipulated and modified to be delivered as adjuvants, to compliment and/or improve the efficacy of an already delivered drug, as well as being delivered in combination, merging two or more chemotherapeutic agents in a single infusion.

Current combinations of chemotherapeutic agents include 5-fluorouracil (5-FU)/leucovorin with oxaliplatin (FOLFOX), 5-FU/leucovorin and irinotecan (FOLFIRI), capecitabine and oxaliplatin (CAPEOX/XELOX) and 5-FU/leucovorin/oxaliplatin and irinotecan (FOLFOXIRI) [9]-[11]. Several key trials undertaken in 2000 established improved efficacy of FOLFOX and FOLFIRI combinations in metastatic CRC. As a result, FOLFOX and FOLFIRI have become the standard of care throughout most of the world, showing moderate superiority when compared to previous chemo-doublet 5-FU/LV, promoting higher overall survival rates and progression-free survival by approximately 12 months. Although proven to be effective in the treatment of CRC, with mortality rates decreasing by approximately 50\% in most parts of the world since 1950 [12]-[14], these cytotoxic chemotherapies are notorious for prompting undesirable neurological and gastrointestinal side-effects (Table 1).

Chronic side-effects often result in dose limitations, and in severe circumstances cessation of anti-cancer treatment, presenting a constant challenge in efficient and tolerable treatment of CRC [15]-[21]. Amongst the most common of these dose-limiting side-effects is chemotherapy-induced diarrhoea (CID) affecting approximately $80 \%$ of patients undergoing chemotherapeutic treatment for colorectal and other gastrointestinal cancers [20] [22]. Moreover, about 5\% of early deaths associated with combination anti-cancer chemotherapy are due to CID [23]. Although there are now established and well-structured guidelines to navigate management of CID, numerous attempts to prevent peripheral and gastrointestinal neurotoxicity have proven ineffective thus far [18] and avenues of treatment are still limited and carry an excessive amount of side-effects including worsening of already chronic gastrointestinal symptoms.

Investigation of the mechanisms underlying adverse effects caused by anti-cancer treatment is imperative for the development of new therapies to target such pathologies as CID, to increase effectiveness of current treatments and improve CRC patients' quality of life.

\section{Chemotherapy-Induced Diarrhoea}

About $40 \%$ of patients receiving standard dose chemotherapy and all patients receiving high dose chemotherapy for gastrointestinal cancers exhibit pain, ulceration, bloating, vomiting and diarrhoea [30] [31]. Recent statistics on colorectal cancer and its treatments indicate that CID occurs at rates as high as $80 \%$ in patients [32]. Diarrhoea is a frequently under-recognised clinical hurdle that significantly affects morbidity and mortality of cancer

Table 1. Neurotoxic and gastrointestinal side-effects associated with anti-cancer chemotherapeutic agents used for the treatment of CRC [24]-[29].

\begin{tabular}{|c|c|}
\hline Drug & Side-effects \\
\hline Carboplatin & Cortical blindness, peripheral sensory neuropathy, nausea, vomiting, constipation and diarrhoea. \\
\hline Cisplatin & $\begin{array}{l}\text { Encephalopathy, headache, stroke, seizures, sensory peripheral neuropathy, Lhermitte’s sign, muscle cramps, } \\
\text { nausea, vomiting and diarrhoea. }\end{array}$ \\
\hline Oxaliplatin & Paraesthesia, sensory peripheral neuropathy, nausea, vomiting, weight loss, constipation and diarrhoea. \\
\hline 5-Fluorouracil & $\begin{array}{l}\text { Cerebellar dysfunction, inflammatory leukoencephalopathy, peripheral neuropathy, nausea, vomiting, } \\
\text { severe diarrhoea and anorexia. }\end{array}$ \\
\hline Irinotecan & $\begin{array}{l}\text { Dysarthria, peripheral sensory neuropathy, palmar-plant erythrodysthesia, nausea, vomiting, severe diarrhoea, } \\
\text { constipation and anorexia. }\end{array}$ \\
\hline
\end{tabular}


patients worldwide [22]. Chemotherapeutic agents most commonly associated with CID include 5-FU, capecitabine, irinotecan and oxaliplatin [32] [33]. Although prevalence and severity of chemotherapy-induced diarrhoea varies greatly based on the combination of chemotherapeutics, certain regimens, especially those containing 5-FU in combination with irinotecan are associated with rates as high as 87\% [22] [34] with one third of patients experiencing severe (grade 3 or 4) (Table 2) diarrhoea [35].

Though CID is a clearly established side-effect of gastrointestinal cancer treatment, little research is underway to determine its underlying mechanisms. CID is believed to be a form, or by-product, of alimentary mucositis; that is, inflammation and ulceration of the mucous membranes of the digestive tract [37]. Alimentary mucositis occurs as a result of altered intestinal microflora and mucin secretion, and is a highly probable contributor to the development of CID; however the pathophysiology behind CID is extensive and complex and probably results from several overlapping mechanisms [37].

Specific anti-cancer treatments can be directly linked to a variety of different types of diarrhoea including secretory, osmotic, malabsorptive, exudative, motility related and inflammatory; all of which may be differentially diagnosed from varying symptomology [37].

Disruption to water and electrolyte balance within the gastrointestinal tract is a key component in the pathophysiology of all types of diarrhoea. Intestinal water balance involves many complex processes and pathways involving inflammatory mediators, hormones and neuropeptides that are strictly regulated to maintain the integrity of the intestinal wall, efficiency of the circulatory and enteric nervous systems [38] [39].

Prominent intestinal mucosal damage is a theme throughout the literature surrounding CID. Toxicity to the rapidly dividing crypt cells of the intestinal epithelium coupled with destruction and depletion of intestinal enzymes is believed to be a major contributor to the decrease in absorption and increase in fluid secretion seen in CID [30]-[34] [40]. Direct harm to the villi and mature cells of the intestinal wall results in a higher proportion of immature secretory cells, this increase in secretion and decrease in absorptive capacity of the villi alters the osmotic gradient within the gut contributing to the onset of diarrhoea [41]. The osmotic component is believed to be attributable to cytotoxic agent-induced damage to colonic crypts, thereby reducing chloride absorption and causing water to be released into the intestinal lumen [41]. Chemotherapy-induced disturbance to intestinal absorptive capacity causes an increase in solutes within the intestinal lumen; this triggers an osmotic shift of water into the lumen resulting in osmotic diarrhoea [30] [34] [41]. When non-absorbable compounds are retained within the lumen, active transport of water and electrons is initiated to maintain luminal potential as well as to flush foreign matter from the gastrointestinal tract. Coupled with this, inflammation throughout the intestines leads to secretion of factors such as prostaglandins, leukotrienes and cytokines further stimulating secretion and increasing damage to the epithelium and disrupting intestinal water and ion transport resulting in hypersecretion [34] [40]. It is has been suggested that acute diarrhoea experienced 24 - 96 hours post-chemotherapeutic infusion is primarily secretory [32]. However, whether all chemotherapy-induced diarrhoeas are due to changes in epithelial surface area unknown. Damage to the enteric nervous system caused by chemotherapeutic treatments [42] [43] might underlie gastrointestinal secretory and motility disturbances involved in pathophysiology of CID. It is also unclear whether different chemotherapeutic regimens are associated with different types of diarrhoea. Moreover, the pathophysiological mechanisms underlying chronic diarrhoea persisting long after the chemotherapy have not been investigated.

Although the likelihood of CID is typically unpredictable, occurrence of CID has been linked to a variety of patient and treatment-associated risk factors (Table 3). It has been found that age $>65$, gender and low performance status are common patient-associated risk factors as well as associated bowel pathologies and genetic polymorphisms that may affect drug metabolism [34]. Accompanying this, certain chemotherapeutic drugs and administration regimes have been found to increase susceptibility to CID. Most prominently the addition of 5-FU and leucovorin to treatments, and combination of 5-FU with irinotecan and oxaliplatin increase both severity and prevalence of CID [43] [44].

Table 2. Common terminology criteria for diarrhoea [36].

\begin{tabular}{rllll}
\hline Toxicity & \multicolumn{1}{c}{ Grade 1 } & \multicolumn{1}{c}{ Grade 2} & \multicolumn{1}{c}{ Grade 3} & Grade 4 \\
\hline \multirow{2}{*}{ Diarrhoea } & $\begin{array}{l}\text { Increase of }<4 \\
\text { stools per day } \\
\text { over baseline. }\end{array}$ & $\begin{array}{l}\text { Increase of } 4-6 \\
\text { stools per day } \\
\text { over baseline. }\end{array}$ & $\begin{array}{l}\text { Increase of }>\text { 7 stools per day } \\
\text { over baseline. Incontinence. } \\
\text { Hospitalization. }\end{array}$ & $\begin{array}{l}\text { Life threatening } \\
\text { consequences. Urgent } \\
\text { intervention indicated. }\end{array}$ \\
\hline
\end{tabular}


Table 3. Risk factors for chemotherapy-induced diarrhoea (modified from [34] [45]-[48]).

\begin{tabular}{ll}
\hline & Elderly $(>65)$ \\
& Female \\
Genetic polymorphisms affecting drug metabolism and distribution such as Gilbert's syndrome, \\
Crigler-Najjar syndrome \\
Biliary obstruction \\
Associated bowel pathology such as inflammatory bowel disease or malabsorption \\
Irinotecan \& 5-FU \\
Weekly chemotherapy schedule \\
Infusional chemotherapy \\
Bolus 5-FU \\
Prior history of CID \\
Prior or concomitant radiotherapy
\end{tabular}

\section{Impact of CID}

Persistent and severe diarrhoea in combination chemotherapy-treated patients often causes malnutrition and dehydration leading to rapid weight loss (cachexia), fatigue, renal failure, haemorrhoids, perianal skin breakdown [49] [50]. In some cases, chemotherapy causes severe intestinal inflammation, bowel wall thickening and ulceration [51]. Thus, CID is a key contributor to the interruptions in optimal clinical outcomes and may lead to life-threatening sequelae [22] [23] [32].

CID is the primary contributor to approximately $60 \%$ of treatment alterations, with about $22 \%$ of patients receiving dose reductions, $28 \%$ of patients having dose delays and complete cessation of treatment in approximately $15 \%$ of patients due to severe diarrhoea during the course of treatment [48] [52]. A direct correlation between cumulative dose and severity of CID has been recognised, with high dose regimens associated with higher reported incidence of CID [20] [29]. Early death rates, occurring in approximately 5\% of patients undergoing anti-cancer treatment, are primarily due to CID leading to severe dehydration [23].

About 53\% of anti-CRC treated patients that receive adjuvant therapies experience grade 3 or 4 CID at some point during the course of treatment and current guidelines recommend aggressive treatment and hospitalization [53]. Thus, CID is fast becoming a major drain on healthcare resources. A recent cost of illness analysis on the economic impact of grade 3 - 4 CID revealed a median hospital stay of 8 days, indicating that CID is a debilitating and costly complication of CRC chemotherapy [48]. The incidence of chronic post-treatment diarrhoea amongst cancer survivors varies from $14 \%$ to $49 \%$ and episodes of diarrhoea can persist for more than 10 years [54] greatly effecting long-term quality of life.

Long-term psychological effects of treatment-related chronic persistent diarrhoea are rarely recognised. Mental and social health of CID sufferers has been shown to be greatly compromised with known psychological effects of uncontrolled CID including anxiety, depression, social isolation and low self-esteem [55]. More than 30\% of CID sufferers experience interference to their daily activities [32].

\section{Treatment of CID}

Current management of CID is based heavily on the nature and progression of the diarrhoea itself. CID may be classified as complicated or uncomplicated, late or early onset and categorised as persistent or non-persistent depending on the National Cancer Institute’s (2009) Common Terminology Criteria for Adverse Effects grading system [32] [36].

Uncomplicated CID can be managed through diet modification and standard dose of recommended drugs such as loperamide, octreotide and tincture of opium in an outpatient setting, however, complicated diarrhoea requires aggressive treatment and hospitalisation where patients are recommended to take anti-diarrhoeal drugs and intravenous fluids [34]. 
The recommendations of a consensus conference on the management of CID were published in 1998 and updated in 2004 [40] [45]. These publications provide guidelines for evaluation and classification of symptoms of CID (Figure 1). Opioid derivatives loperamide and deodorized tincture of opium (DTO), and octreotide are the only drugs recommended in the updated treatment guidelines, due to lack of efficacy and insufficient evidence for benefits of other therapeutic approaches such as prophylactic treatments [22]. Although the National Cancer Institute's Common Terminology Criteria for Adverse Effects grading system has been updated on several occasions, CID management and treatment guidelines have not been changed since 2004. A consensus working statement published in 2007 offered several clinical recommendations and improvement; however no changes to the treatment of CID have been made [35].

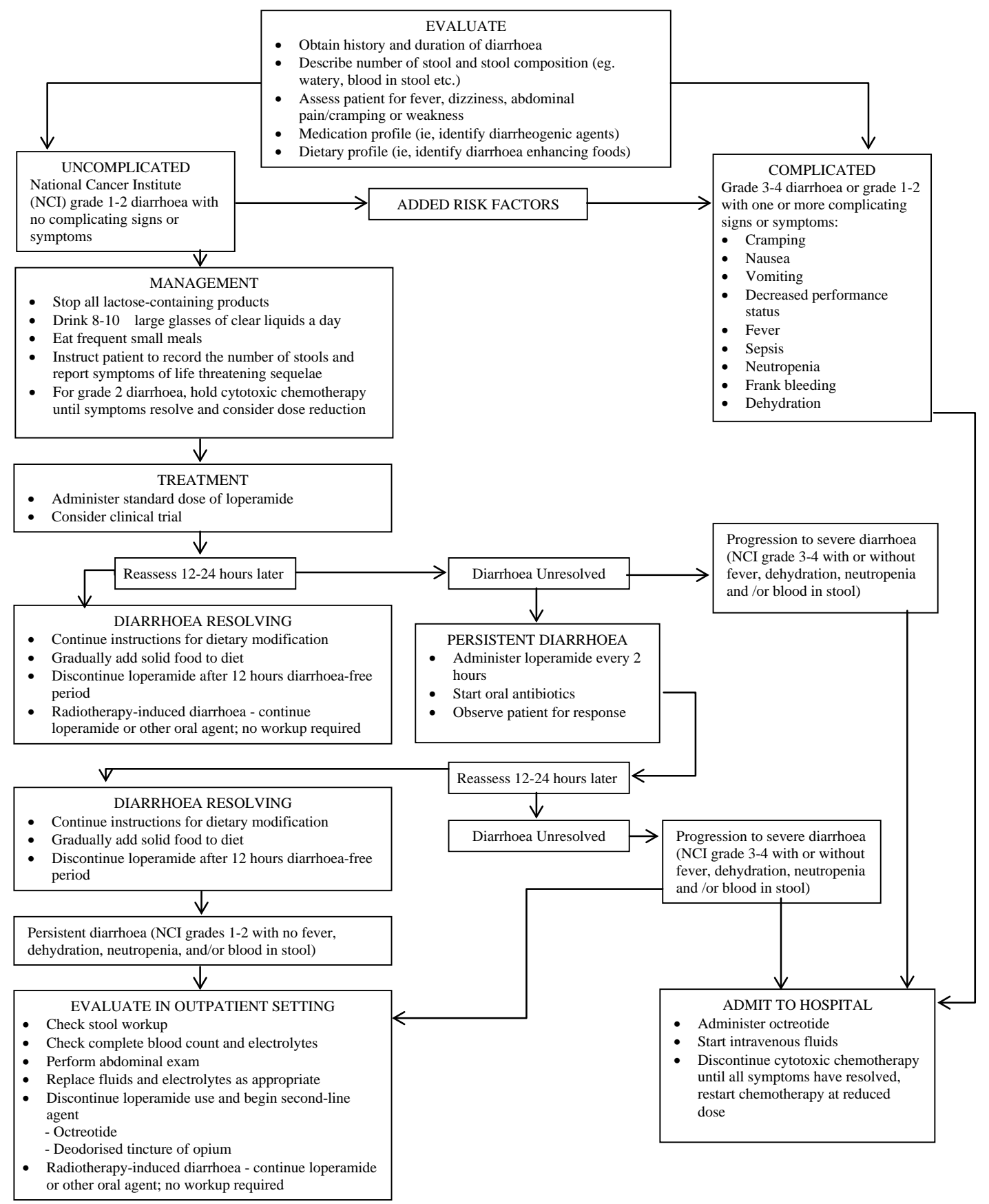

Figure 1. Guidelines for treatment of chemotherapy-induced diarrhoea (modified from [22] [32]). 
Until recently the significance of chemotherapy-induced diarrhoea and its impact on regimen designation and treatment efficiency has been greatly underestimated. As a result current treatments available are limited and carry a wide variety of adverse effects including further gastrointestinal symptoms (Table 4).

\section{National Cancer Institute Guideline-Based Treatment for CID}

\subsection{Loperamide}

Loperamide is a non-analgesic agonist that decreases intestinal motility through an action at $\mu$-opioid receptors of the myenteric plexus [32]. High dose loperamide alleviates diarrhoea associated with chemotherapeutic administration and is the standard first line therapy for CID [22]. However, it is associated with high levels of resistance and failure, specifically when used with irinotecan, and has a variety of side-effects including severe constipation, abdominal pain, dizziness, and rashes and worsening of already present bloating, nausea and vomiting [32] [56]. Clinical studies have also reported incidents of paralytic ileus, in association with abdominal distension occurring in patients administered a very high dose of loperamide [34] [57].

\subsection{Octreotide}

Loperamide-refractory and complicated diarrhoea are both treated with octreotide [22], an indirect anti-motility substance. Octreotide is a synthetic somatostatin analogue that inhibits specific gut hormones to increase intestinal transit time promoting absorption [38] [49] [58] as well as hyperpolarizing secretomotor neurons within the enteric nervous system to inhibit secretion and promote net absorption [58]. Octreotide has shown to be effective in decreasing CID in clinical trials [38]. However severe adverse effects such as slow and/or uneven heartbeat, severe constipation, severe stomach pain, enlarged thyroid, vomiting, nausea, headache and dizziness occur in more than $10 \%$ of patients treated with octreotide [59]. Octreotide is generally reserved as a second line treatment for patients who are unresponsive to loperamide after 48 hours, despite loperamide escalation [32].

\subsection{Deodorised Tincture of Opium}

Deodorized tincture of opium (DTO) similarly to loperamide, works by activating $\mu$-opioid receptors within the

Table 4. Current treatments and their side-effects for chemotherapy-induced diarrhoea.

\begin{tabular}{|c|c|c|c|}
\hline Treatment & Mechanism & Side-Effects & References \\
\hline Loperamide & $\begin{array}{l}\text { Synthetic opiate derivative } \mu \text {-opioid receptor } \\
\text { agonist that slows intestinal peristalsis, increases } \\
\text { intestinal transit time to promote fluid } \\
\text { reabsorption. Also exhibits anti-secretory } \\
\text { effects through inhibition of thromboxane-A2. }\end{array}$ & $\begin{array}{l}\text { Stomach pain and bloating, ongoing or worsening } \\
\text { of diarrhoea, watery and bloody diarrhoea, severe } \\
\text { skin reactions (blistering and peeling), nausea, } \\
\text { vomiting, dizziness, drowsiness, severe } \\
\text { constipation and paralytic ileus. }\end{array}$ & $\begin{array}{l}{[32][34]} \\
{[38][47]} \\
{[56][80]}\end{array}$ \\
\hline Octreotide & $\begin{array}{l}\text { Synthetically engineered somatostatin analogue } \\
\text { designed to bind to somatostatin receptors; } \\
\text { inhibits adenylyl cyclase to reduce secretion of } \\
\text { pancreatic and intestinal hormones, increases } \\
\text { intestinal transit time and promotes } \\
\text { reabsorption. }\end{array}$ & $\begin{array}{l}\text { Easy bruising and unusual bleeding (nose, } \\
\text { mouth, vagina and rectum), purple/red } \\
\text { pinpoint spots under skin, slow and/or uneven } \\
\text { heart beats, severe constipation, severe stomach } \\
\text { pain, enlarged thyroid, vomiting, nausea, } \\
\text { headache and dizziness. }\end{array}$ & $\begin{array}{l}{[22][32]} \\
{[38][47]} \\
{[48][59]} \\
{[80]}\end{array}$ \\
\hline $\begin{array}{l}\text { Tincture } \\
\text { of opium }\end{array}$ & $\begin{array}{l}\text { Similar to loperamide, acts by activating } \\
\mu \text {-opioid receptors to slow intestinal peristalsis } \\
\text { thereby increasing intestinal transit time and } \\
\text { promoting fluid reabsorption. }\end{array}$ & $\begin{array}{l}\text { Vomiting, nausea and light headedness, } \\
\text { stomach/abdominal pain, painful/difficult } \\
\text { urination, seizures, itching and swelling of } \\
\text { the face, tongue and throat, psychological } \\
\text { dependence, physical dependence, miosis } \\
\text { and respiratory depression. }\end{array}$ & [22] [34] \\
\hline Budesonide & $\begin{array}{l}\text { Orally administered synthetic steroid with } \\
\text { anti-inflammatory effects. Helps to restore } \\
\text { mucosal function and improve intestinal fluid } \\
\text { reabsorption. Has inhibitory effect on mucosal } \\
\text { prostaglandins. }\end{array}$ & $\begin{array}{l}\text { Increased blood pressure, headache, thinning } \\
\text { of the skin, easy bruising, muscle pain, stomach } \\
\text { pain, indigestion, mild skin rash, changes to } \\
\text { menstrual cycle. }\end{array}$ & $\begin{array}{l}{[46][61]} \\
{[63]}\end{array}$ \\
\hline Atropine & $\begin{array}{l}\text { Competitive antagonist at muscarinic } \\
\text { receptors. Helps to suppress the cholinergic } \\
\text { effects of irinotecan. }\end{array}$ & $\begin{array}{l}\text { Allergic reactions (swelling of the lips, tongue and } \\
\text { face), irregular or fast heart rate, rash or flushing, eye } \\
\text { pain, headache, dizziness, blurred vision, bloating, } \\
\text { nausea, heartburn, constipation, weakness, difficulty } \\
\text { urinating. }\end{array}$ & {$[60]-[62]$} \\
\hline
\end{tabular}


gastrointestinal tract to slow intestinal peristalsis, thereby increasing intestinal transit time and promoting fluid reabsorption [34]. Currently there are no studies demonstrating the efficacy of DTO in treatment of CID, but it is still a widely used anti-diarrheal drug and may be considered as a second-line therapy for persistent and uncomplicated diarrhoea [34]. DTO contains $10 \mathrm{mg} / \mathrm{ml}$ of morphine, making it one of the most potent forms of orally administered morphine available by prescription. Side-effects of DTO range from euphoria or dysphoria to vomiting, nausea, light headedness, stomach/abdominal pain, painful/difficult urination as well as seizures, itching and swelling of the face, tongue and throat. DTO has also been linked to psychological and physical dependence, meiosis and respiratory depression [22] [34].

\section{Prophylactic Measures}

\subsection{Atropine}

Atropine is a competitive antagonist at muscarinic receptors that helps to suppress the cholinergic effects of secretory diarrhoea. Atropine functions by inhibiting the muscarinic actions of acetylcholine released by cholinergic nerve fibres innervating gastrointestinal smooth muscles, as well as inhibiting the actions of cholinergic secretomotor neurons innervating the mucosa. Dosage ranges from 0.25 - $1 \mathrm{mg}$ and can be delivered intravenously or subcutaneously as either prophylaxis or treatment for CID, to a maximum cumulative dose of $1.2 \mathrm{mg}$ [60]. It has been found that subcutaneous administration of atropine prior to chemotherapeutic treatment was effective at reducing CID [60] [61]. However atropine administration is linked to swelling of the lips, tongue and face, irregular or fast heart rate, rash or flushing, eye pain, headache, dizziness, blurred vision, bloating, nausea, heartburn, constipation, weakness, difficulty urinating [60]-[62].

\subsection{Budesonide}

Budesonide is an orally administered synthetic steroid with anti-inflammatory effects, commonly used in patients with inflammatory bowel disease. It works to restore mucosal function and improve intestinal fluid reabsorption as well as having an inhibitory effect on mucosal prostaglandins. Suppression of inflammation throughout the bowel could potentially contribute to reductions in the occurrence of CID; however published data revealed no significant decreases in incidence of CID from concurrent budesonide and loperamide treatment [63]. Furthermore budesonide has been linked to increased blood pressure, headache, thinning of the skin, easy bruising, muscle pain, stomach pain, indigestion, mild skin rash, and changes to menstrual cycle [46] [61] [63].

\subsection{Antibiotics}

Several studies have investigated the effectiveness of antibiotic therapy to combat irinotecan-induced diarrhoea [64]. Results surrounding antibiotic use in irinotecan-induced diarrhoea remain controversial. Several studies indicated that elimination of $\beta$-glucoronidase producing microflora through the use of antibiotics namely penicillin, streptomycin, cefixime, ceftriaxone, neomycin and levofloxacin may decrease incidence and severity of CID [65]-[67]. In contrary, non-significant reductions in severity and frequency of diarrhoea accompanied by substantially higher rates of grade 2 diarrhoea were found [68]. Moreover, contention over the use of antibiotics in immune compromised patients for risk of Clostridium difficile (C. difficile) infection causing both nosocomial and antibiotic-associated diarrhoea is evident throughout literature [46] [65] [69]. C. difficile is a prominent and potentially life threatening infection that results from disturbance of normal bacterial flora in the colon, triggering release of toxins that cause mucosal inflammation and damage. C. difficile infection is most frequent amongst hospitalized patients and it is well known that colorectal cancer, abdominal surgery, as well as a weakened immune system as a result of chemotherapy, increases susceptibility to C. difficile infection [70] [71].

\subsection{Glutamine}

Glutamine is an amino acid found within the gastrointestinal tract, it acts as a major energy source for enterocytes as well as playing an important role in gut integrity and immune responses [72]. It is believed that glutamine can stimulate intestinal mucosa growth, and therefore may reduce gastrointestinal toxicity [32] [73] [74]. Several studies over the last decade have investigated the incidence and severity of CID in patients receiving 
prophylactic oral and intravenous glutamine [75]-[79]. It was reported that intravenous administration of $20 \mathrm{~g}$ glutamine reduced plasma endotoxin levels and decreased severity of CID [77]. However a more recently conducted meta-analysis concluded that, although glutamine may reduce the duration of CID, it does not reduce its severity [78]. Furthermore, a trial involving high-dose chemotherapy and glutamine-containing intravenous solutions showed significantly higher incidence of relapse and death in patients receiving glutamine [79].

\section{Emerging \& Potential Treatments for CID}

Given that current treatments for CID have limited efficacy and a wide range of adverse effects, the search for and use of alternative anti-diarrhoeal agents with few or no side-effects is essential. Several emerging and already existing treatments for other conditions associated with acute and chronic diarrhoea, such as irritable bowel syndrome (IBS), travellers' diarrhoea and other conditions could be considered and tested for the treatment of CID.

\subsection{Adsorbents}

Adsorbent substances are emerging as promising avenues in the treatment of CID. Adsorbents work by collecting excess materials on their surface and transporting them through the excretion process. Activated charcoal has long been used in the treatment of acute poisoning and is under investigation as a remedy for the late onset diarrhoea experienced after 5-FU and irinotecan infusions [81]. AST-120 also known as kremazin, a carbon-based adsorbent that is believed to absorb uremic toxins, such as indoxyl sulphate, in the gut has been explored in both cancer patients with irinotecan-induced diarrhoea and nonconstipated IBS sufferers [82] [83]. AST-120 has been found to be safe and well-tolerated, effective in reducing pain and bloating in nonconstipated IBS sufferers and to ameliorate irinotecan-induced diarrhoea without disrupting clearance of irinotecan metabolites.

\subsection{Chloride Channel Inhibitors}

Chloride is an essential ion in intestinal secretion and absorption. Secretory diarrhoea, such as that experienced in irinotecan-treated patients, results from a combination of excessive secretion and reduced absorption in the intestinal lumen [84] [85]. Excessive fluid secretion is driven by active chloride secretion, followed by secondary movement of water and sodium into the intestine. Deliberate inhibition of calcium-activated chloride channels located on enterocytes throughout the intestines reduces excretion of chloride into the intestinal lumen and consequently decreases the presence of water and sodium, diminishing the symptoms of diarrhoea [86].

\subsection{Kappa Opioid Receptor Agonists}

Opioid receptors $(\mu$ (mu), $\delta$ (delta) and $\kappa$ (kappa)) located throughout the peripheral and central nervous systems participate in inhibition of perception of noxious stimuli from the gastrointestinal tract [87]. Although effective as anti-diarrhoeal agents both $\mu$ and $\delta$ agonists have many adverse effects such as constipation and opioid dependence, which impede their general use in clinical practice [87]. However, $\kappa$-opioid receptor agonists seem to be devoid of these symptoms.

Asimadoline is a highly selective and potent $\kappa$-opioid receptor agonist that is predominantly peripherally restricted at doses below $5 \mathrm{mg}$ [88]. In clinical trials conducted in IBS patients it displayed a significant improvement in frequency/urgency of stools and pain free days and adequate relief of pain scores [89] [90]. Although there was no significant improvement in primary end point (number of months accrued with adequate relief of pain), asimadoline appeared to be well tolerated and produced overall improvement of gastrointestinal symptoms, including diarrhoea [90] highlighting that it could be used as a potential therapeutic for CID given that pain relief is not a primary concern in CID sufferers.

\subsection{Enkephalinase Inhibitors}

Enkephalins are endogenous neurotransmitters found throughout the enteric nervous system. Known to be pro-absorptive and anti-secretory in nature, enkephalins act on $\delta$-opioid receptors, increasing chloride absorption and inhibiting adenylate cyclase to reduce intestinal secretion. Endogenous enkephalins are rapidly degraded by 
enkephalinase. Inhibition of enkephalinase has recently been tested for anti-secretory effects against numerous secretagogues including cholera toxin and prostaglandins. Racecadotril is a powerful enkephalinase inhibitor with its active metabolite thiorphan being effective in clinical management of acute diarrhoea in both adults and children [91] [92]. Clinical trials of racecadotril have primarily been undertaken in patients with acute diarrhoea of presumed infectious origin and chronic HIV-related diarrhoea. Racecadotril significantly decreases mean stool output and duration of acute diarrhoea in both adults and infants when compared to placebo [93] [94], and has a similar efficacy to loperamide [91] [95] [96], but appears to be better tolerated than loperamide in both adults and children [97].

\subsection{Cannabinoids}

The effects of cannabinoids are primarily mediated by cannabinoid receptors, a widely expressed class of G-protein coupled receptors. Currently known two receptor subtypes, $\mathrm{CB}_{1}$ and $\mathrm{CB}_{2}$, are the main constituent of the endocannabinoid system. Recent studies have found that endocannabinoids acting on myenteric cannabinoid receptors can inhibit colonic propulsion [98] [99]. Dronabinol, a non-selective cannabinoid receptor agonist inhibits colonic motility in healthy subjects [98] [99] and patients with IBS-related diarrhoea [100].

\section{Conclusion}

Combination therapies now represent the standard first-line of treatment in CRC worldwide, with statistics showing great potential to increase overall survival in locally resected stage III CRC. Chemotherapy-induced gastrointestinal toxicity persists as a major contributor to dose delays, reductions and treatment terminations. Chemotherapy-induced diarrhoea is one of the most common disruptions in clinical management of CRC, affecting a vast majority of patients being treated with combination or adjuvant therapies containing 5-FU and irinotecan. Current treatments for CID are limited and have an abundance of concomitant symptoms; but novel and emerging anti-diarrhoeal treatments may present an additional unexplored avenue of treatments for CID sufferers. Ongoing investigation to identify potential targets and innovative treatment agendas to decrease chemotherapy-related toxicity is essential to improve clinical outcomes and quality of life amongst CID sufferers.

\section{References}

[1] Arndt, V., Merx, H., Stegmaier, C., Ziegler, H. and Brenner, H. (2004) Quality of Life in Patients with Colorectal Cancer 1 Year after Diagnosis Compared with the General Population: A Population-Based Study. Journal of Clinical Oncology, 22, 4829-4836. http://dx.doi.org/10.1200/JCO.2004.02.018

[2] Lochhead, P. and El-Omar, E.M. (2008) Gastric Cancer. British Medical Bulletin, 85, 87-100. http://dx.doi.org/10.1093/bmb/ldn007

[3] World Health Organisation (2011) CancerStats Cancer Worldwide. International Agency for Research on Cancer, World Health Organisation. http://publications.cancerresearchuk.org/downloads/Product/CS_CS_WORLD.pdf

[4] Economists Intelligence Unit (2009) Breakaway: The Global Burden of Cancer-Challenges and Opportunities, a Report from the Economist Intelligence Unit. The Economist. https://assets-livestrong-org.s3.amazonaws.com/media/site proxy/data/c49ced3068f7205319cb1edf653dd91e0baee3ba .pdf

[5] Isomoto, H. (2010) Global Dissemination of Endoscopic Submucosal Dissection for Early Gastric Cancer. Internal Medicine, 49, 251-252. http://dx.doi.org/10.2169/internalmedicine.49.3074

[6] Saidi, H., Nyaim, E.O., Githaiga, J.W. and Karuri, D. (2008) Surgery Trends in Kenya, 1993-2005. World Journal of Surgery, 32, 217-223. http://dx.doi.org/10.1007/s00268-007-9301-2

[7] Gao, F.H., Hu, X.H., Li, W., Liu, H., Zhang, Y.J., Gou, Z.Y., Xu, M.H., Wang, S.T., Jiang, B., Liu, F., Zhao, Y.Z., Fang, Y., Chen, F.Y. and Wu, Y.L. (2010) Oridonin Induces Apoptosis and Senescence in Colorectal Cancer Cells by Increasing Histone Hyperacetylation and Regulation of p16, p21, p27 and c-myc. BMC Cancer, 10, 610-621. http://dx.doi.org/10.1186/1471-2407-10-610

[8] Yao, Y., Zhao, H., Sun, Y., Lin, F., Tang, L. and Chen, P. (2008) Combined Chemotherapy of Hydroxycampothecin with Oxaliplatin as an Adjuvant Treatment for Human Colorectal Cancer. Tohoku Journal of Experimental Medicine, 215, 267-278. http://dx.doi.org/10.1620/tjem.215.267

[9] Jeon, H.J., Woo, J.H., Lee, H.Y., Park, K.J. and Choi, H.J. (2011) Adjuvant Chemotherapy Using the FOLFOX Regimen in Colon Cancer. Journal of the Korean Society of Coloproctology, 27, 140-146. 
http://dx.doi.org/10.3393/jksc.2011.27.3.140

[10] Karaca-Mandic, P., McCullough, J.S., Siddiqui, M.A., Van Houten, H. and Shah, N.D. (2011) Impact of New Drugs and Biologics on Colorectal Cancer Treatment and Costs. Journal of Oncology Practice, 7, 30-37. http://dx.doi.org/10.1200/JOP.2011.000302

[11] Takashima, A., Yamada, Y., Nakajima, T.E., Kato, K., Hamaguchi, T. and Shimada, Y. (2009) Standard First-Line Chemotherapy for Metastatic Gastric Cancer in Japan Has Met the Global Standard: Evidence From Recent Phase III Trials. Gastrointestinal Cancer Research, 3, 239-244.

[12] Herszenyi, L. and Tulassay, Z. (2010) Epidemiology of Gastrointestinal and Liver Tumors. European Review for medical and Pharmalogical Sciences, 14, 249-258.

[13] Jemel, A., Center, M.M., DeSantis, C. and Ward, E.M. (2010) Global Patterns of Cancer Incidence and Mortality Rates and Trends. Cancer Epidemiology Biomarkers \& Prevention, 19, 1893-1907. http://dx.doi.org/10.1158/1055-9965.EPI-10-0437

[14] Muss, H.B. and Bynum, D.L. (2012) Adjuvent Chemotherapy in Older Patients with Stage III Colon Cancer: An Underused Lifesaving Treatment. Journal Clinical Oncology, 30, 2576-2578. http://dx.doi.org/10.1200/JCO.2012.42.3780

[15] Baek, K.L., Lee, J., Park, S.H., Park, J.O., Park, Y.S., Lim, H.Y., Kiang, W.K., Cho, Y.B., Yun, S.H., Kim, H.C., Lee, Y.W. and Chun, H.K. (2010) Oxaliplatin-Induced Chronic Peripheral Neurotocixity: A Prospective Analysis in Patients with Colorectal Cancer. Cancer Research and Treatment, 45, 185-190. http://dx.doi.org/10.4143/crt.2010.42.4.185

[16] Cathomas, R., Koberle, D., Ruhstaller, T., Mayer, G., Rass, A., Mey, U. and Moos, R.V. (2010) Heated (37C) Oxaliplatin Infusion in Combination with Capecitabine for Metastatic Colorectal Carcinoma: Can It Reduce Neuropathy? Support Care Cancer, 18, 1263-1270. http://dx.doi.org/10.1007/s00520-009-0740-1

[17] Lehky, T.J., Leonard, G.D., Wilson, R.H., Grem, J.L. and Floeter, M.K. (2004) Oxaliplatin-Induced Neurotoxicity: Acute Hyperexcitablilty and Chronic Neuropathy. Muscle \& Nerve, 29, 387-392. http://dx.doi.org/10.1002/mus.10559

[18] McWhinney, S.R., Goldberg, R.M. and McLoeod, H.L. (2009) Platinum Neurotoxicity Pharmacogenetics. Molecular Cancer Theories, 8, 10-16. http://dx.doi.org/10.1158/1535-7163.MCT-08-0840

[19] Quasthoff, S. and Hartung, H.S. (2002) Chemotherapy-Induced Peripheral Neuropathy. Journal of Neurology, 249, 917. http://dx.doi.org/10.1007/PL00007853

[20] Verstappen, C.C.P., Heimans, J.J., Hoekman, K. and Postma, T.J. (2003) Nuerotoxic Complocations of Chemotherapy in Patients with Cancer, Clinical Signs and Optimal Management. Therapy in Practice, 63, 1549-1563.

[21] Leonard, G.D., Wright, M.A., Quinn, M.C., Fioravanti, S., Harold, N., Schuler, B., Thomas, R.R. and Grem, J.L. (2005) Survey of Oxaliplatin-Associated Neurotoxicity Using an Interview-Based Questionnaire in Patients with Metastatic Colorectal Cancer. BMC Cancer, 5, 116.

[22] Benson III, A.B., Ajani, J.A., Catalano, R.B., Engelking, C., Kornlau, S.M., Martenson Jr., J.A., McCallum, R., Mitchell, E.P., O’Dorsio, T.M., Vokes, E.E. and Wadler, S. (2004) Recommended Guidelines for the Treatment of Cancer Treatment- Induced Diarrhea. Journal of Clinical Oncology, 22, 2918-2926. http://dx.doi.org/10.1200/JCO.2004.04.132

[23] Rothenberg, M.L., Meropol, N.J., Poplin, E.A., Van Cutsem, E. and Wadler, S. (2001) Mortality Associated with Irinotecan Plus Bolus Fluorouracil/Leucovorin: Summary Findings of an Independent Panel. Journals of Clinical Oncology, 19, 3801-3807.

[24] Chau, I. and Cunningham, D. (2002) Chemotherapy in Colorectal Cancer: New Options and New Challenges. British Medical Bulletin, 64, 159-180. http://dx.doi.org/10.1093/bmb/64.1.159

[25] Pietrangeli, A., Leandri, M., Terzoli, E., Jandolo, B. and Garufi, C. (2006) Persistence of High-Dose Oxaliplatin-Induced Neuropathy at Long-Term Follow-Up. European Neurology, 56, 13-16. http://dx.doi.org/10.1159/000094376

[26] Conroy, T., Paillot, B., Franois, E., Bugat, R., Jacob, J.H., Stein, U., Nasca, S., Metges, J.P., Rixe, O., Michel, P., Magherini, E., Hua, A. and Deplanque, G. (2005) Irinotecan Plus Oxaliplatin and Leucovorin-Modulated Fluorouracil in Advanved Pancreatic Cancer-A Groupe Tumeurs Digestives of the Federation National des Centres de Lutte Contre le Cancer Study. Journal of Clinical Oncology, 23, 1228-1236. http://dx.doi.org/10.1200/JCO.2005.06.050

[27] Garcia, I.S., Rueda, A. and Alba, E. (1999) Irinotecan-Induced Central Nervous System Toxicity: A Case Report. Journal of the National Cancer Institute, 91, 647. http://dx.doi.org/10.1093/jnci/91.7.647

[28] Gholam, D., Giacchetti, S., Brezault-Bonnet, C., Bouchahda, M., Hauteville, D., Adam, R., Ducot, B., Ghemard, A., Kustlinger, F., Jasmin, C. and Levi, F. (2006) Chronomodulated Irinotecan, Oxaliplatin and Leucovorin-Modulated 5-Fluoruoracil as Ambulatory Salvage Therapy in Patients with Irinotecan- and Oxaliplatin-Resistant Metatastic Colorectal Cancer. The Oncologist, 11, 1072-1080.

[29] Dvorak, A.M., Onderdonk, A.B., McLeod, R.S., Monahan-Earley, R.A., Cullen, J., Antonioli, D.A., Blair, J.E., Morgan, E.S., Cisneros, R.L., Estrellla, P., Cohen, Z. and Silen, W. (1993) Axonal Necrosis of Enteric Automatic Nerves in Continent Heal Pouches Implications for Pathogenesis of Crohn’s Disease. Annals of Surgery, 217, 260-271. 
http://dx.doi.org/10.1097/00000658-199303000-00008

[30] Stringer, A.M., Gibson, R.J., Logan, R.M., Bowen, J.M. and Yeoh, A.S. (2007) Chemotherapy-Induced Diarrhoea Is Associated with Changes in the Luminal Environment in the DA Rat. Experimental Biology \& Medicine, 232, 96-106.

[31] Stringer, A.M., Gibson, R.J., Bowen, J.M., Logan, R.M., Ashton, K., Yeoh, A.S.J., Al-Dasooqi, N. and Keefe, D.M.K. (2009) Irinotecan-Induced Mucositis Manifesting as Diarrhoea Corresponds with Amended Intestinal Flora and Mucin Profile. International Journal of Experimental Pathology, 90, 489-499. http://dx.doi.org/10.1111/j.1365-2613.2009.00671.x

[32] Stein, A., Voigt, W. and Jordan, K. (2010) Review: Chemotherapy-Induced Diarrhea: Pathophysiology, Frequency and Guideline Based Management. Therapeutic Advances in Medical Oncology, 2, 51-63. http://dx.doi.org/10.1177/1758834009355164

[33] Keefe, D.M., Schubert, M.M., Elting, L.S., Sonis, S.T., Epstein, J.B., Raber-Durlacher, J.E., Migliorati, C.A., McQuire, D.B., Hutchins, R.D. and Peterson, D.E. (2007) Updates Clinical Practice Guidelines for the Prevention and Treatment of Mucositis. Cancer, 109, 820-832. http://dx.doi.org/10.1002/cncr.22484

[34] Richardson, G.G. and Dobish, R.R. (2007) Chemotherapy Induced Diarrhea. Journal of Oncology Pharmacy Practice, 13, 181-198. http://dx.doi.org/10.1177/1078155207077335

[35] Maroun, J.A., Anthony, L.B., Blais, N., Burkes, R., Dowden, S.D., Dranitsaris, G., Samson, B., Shah, A., Thirlwell, M.P., Vincent, M.D. and Wong, R. (2007) Prevention and Management of Chemotherapy-Induced Diarrhoea in Patients with Colorectal Cancer: A Consensus Statement by the Canadian Working Group on Chemotherapy-Induced Diarrhea. Current Oncology, 14, 14-20. http://dx.doi.org/10.3747/co.2007.96

[36] National Cancer Institute (2009) Common Terminology Criteria for Adverse Events (CTCAE). Version 4.0. US Department of Health and Human Services, National Institutes of Health. http://evs.nci.nih.gov/ftp1/CTCAE/CTCAE_4.03_2010-06-14_QuickReference_5x7.pdf

[37] Stringer, A.M., Gibson, R.J., Bowen, J.M., Logan, R.M., Yeoh, A.S.J. and Keefe, M.K. (2007) Chemotherapy-Induced Mucositis: The Role of Gastrointestinal Microflora and Mucins in the Luminal Environment. The Journal of Supportive Oncology, 5, 259-267.

[38] Gibson, R.J. and Keefe, D.M.K. (2006) Cancer Chemotherapy-Induced Diarrhoea and Constipation: Mechanisms of Damage and Prevention Strategies. Supportive Care in Cancer, 14, 890-900. http://dx.doi.org/10.1007/s00520-006-0040-y

[39] Baldi, F., Bianco, M., Nardone, G., Pilotto, A. and Zamparo, E. (2009) Focus on Acute Diarrhoeal Disease. World Journal of Gastroenterology, 15, 3341-3348.

[40] Ferrell, B.R. and Coyle, N. (2005) Textbook of Palliative Nursing. Oxford University Press, Oxford.

[41] Castro-Rodriguez, J.A., Salazar-Lindo, E. and Leon-Barua, R. (1997) Differentiation of Osmotic and Secretory Diarrhoea by Stool Carbohydrate and Osmolar Gap Measurements. Archives of Disease in Childhood, 77, 201-205. http://dx.doi.org/10.1136/adc.77.3.201

[42] Vera, G., Castillo, M., Cabezos, P.A., Chairlone, A., Martin, M.I., Gori, A., Paquinelli, G., Barbara, G., Staghelleni, V., Corinaldesi, R., De Giorgio, R. and Abalo, R. (2011) Enteric Neuropathy Evoked by Repeated Cisplatin in the Rat. Neurogastroenterology \& Motility, 23, 370-e162. http://dx.doi.org/10.1111/j.1365-2982.2011.01674.X

[43] Wafai, L., Taher, M., Jovanovska, V., Bornstein, J.C., Dass, C.R. and Nurgali, K. (2013) Effects of Oxaliplatin on Mouse Myenteric Neurons and Colonic Motility. Frontiers in Neuroscience, 7, 1-8. http://dx.doi.org/10.3389/fnins.2013.00030

[44] Devila, M. and Bresalier, R.S. (2008) Gastrointestinal Complication of Oncologic Therapy. Nature Reviews Gastroenterology and Hepatology, 5, 682-696. http://dx.doi.org/10.1038/ncpgasthep1277

[45] Wadler, S., Benson III, A.B. and Engelking, C. (1998) Recommended Guidelines for the Treatment of ChemotherapyInduced Diarrhea. Journal of Clinical Oncology, 16, 3169-3178.

[46] Yang, X., Hu, Z. and Chan, S.Y. (2005) Novel Agents that Potentially Inhibit Irinotecan-Induced Diarrhea. Current Medicinal Chemistry, 12, 1343-1358. http://dx.doi.org/10.2174/0929867054020972

[47] Saltz, L.B. (2003) Understanding and Managing Chemotherapy Induced Diarrhea. Journal of Supportive Oncology, 1, 35-46.

[48] Dranitsaris, G., Maroun, J. and Shah, A. (2005) Estimating the Cost of Illness in Colorectal Cancer Patients Who Were Hospitalized for Severe Chemotherapy-Induced Diarrhea. Canadian Journal of Gastroenterology, 19, 83-87.

[49] Mitchell, E.P. (2006) Gastrointestinal Toxicity of Chemotherapeutic Agents. Seminars in Oncology, 33, 106-120. http://dx.doi.org/10.1053/j.seminoncol.2005.12.001

[50] Shafi, M.A. and Bresalier, R.S. (2010) The Gastrointestinal Complications of Oncologic Therapy. Gastroenterology Clinics of North America, 39, 629-647. http://dx.doi.org/10.1016/j.gtc.2010.08.004 
[51] Kuebler, J.P., Colengalo, L., O’Connell, M.J., Smith, R.E., Yothers, G., Begovic, M., Robinson, B., Seay, T.E. and Wolmark, N. (2007) Severe Enteropathy among Patients with Stage II/III Colon Cancer Treated on a Randomized Trial of Bolus 5-FU/Leucovorin Plus or Minus Oxaliplatin. Cancer, 110, 1945-1950. http://dx.doi.org/10.1002/cncr.23013

[52] Arbuckle, R.B., Huber, S.L. and Zacker, C. (2000) The Consequences of Diarrhea Occurring during Chemotherapy for Colorectal Cancer: A Retrospective Study. The Oncologist, 5, 250-259. http://dx.doi.org/10.1634/theoncologist.5-3-250

[53] Janinis, J., Papakostas, P., Samelis, G., Skarlos, D., Papagianopoulos, P. and Fountzilas, G. (2000) Second-Line Chemotherapy with Weekly Oxaliplatin and High-Dose 5-Fluorouracil with Folinc Acid in Metastatic Colorectal Carcinoma: A Hellenic Cooperative Oncology Group (HeCOG) Phase II Feasibility Study. Annals of Oncology, 11, 163-167. http://dx.doi.org/10.1023/A:1008397109048

[54] Denlinger, C.S. and Barsevick, A.M. (2009) The Challenges of Colorectal Cancer Survivorship. Journal of the National Comprehensive Cancer Network, 7, 883-894.

[55] Viele, C.S. (2003) Overview of Chemotherapy-Induced Diarrhoea. Seminars in Oncology Nursing, 19, 2-5. http://dx.doi.org/10.1053/j.soncn.2003.09.007

[56] Lenfers, B.H.M., Loeffler, T.M., Droege, C.M. and Hausmen, T.U. (1999) Substantial Activity of Budesonide in Patients with Irinotecan (CPT-11) and 5-Fluorouracil Induced Diarrhea and Failure of Loperamide Treatment. Annals of Oncology, 10, 1251-1251. http://dx.doi.org/10.1023/A:1008390308416

[57] Sharma, R., Tobin, P. and Clarke, S.J. (2005) Management of Chemotherapy-Induced Nausea, Vomiting, Oral Mucositis and Diarrhoea. The Lancet Oncology, 6, 93-102. http://dx.doi.org/10.1016/S1470-2045(05)01735-3

[58] Hogenauer, C., Aichnichler, S., Sanat Ana, C., Prter, J. and Fordtran, J. (2002) Effect of Octreotide on Fluid Absorption and Secretion by the Normal Human Jejunum and Ileum in Vivo. Alimentary Pharmacology \& Therapeutics, 16, 769-777. http://dx.doi.org/10.1046/j.1365-2036.2002.01228.x

[59] Hovind, P., Simonsen, L. and Bulow, J. (2010) Decreased Leg Glucose Uptake during Exercise Contributes to the Hyperglyceamic Effects of Octreotide. Clinical Physiology and Functional Imaging, 30, 141-145. http://dx.doi.org/10.1111/j.1475-097X.2009.00917.x

[60] Yumuk, P.F., Aydin, S.Z. and Dane, F. (2004) The Absence of Early Diarrhea with Atropine Premedication during Irinotecan Therapy in Metastatic Colorectal Patients. International Journal of Colorectal Disease, 19, 609-610. http://dx.doi.org/10.1007/s00384-004-0613-5

[61] Jansman, F.G.A., Sleijfer, D.T., de Graaf, J.C., Coenen, J.L.L.M. and Brouwers, J.R.B.J. (2001) Management of Chemotherapy-Induced Adverse Effects in the Treatment of Colorectal Cancer. Drug Safety, 24, 353-367. http://dx.doi.org/10.2165/00002018-200124050-00002

[62] Bengt, G. (2005) Benefit-Risk Assessment of Irinotecan in Advanced Colorectal Cancer. Drug Safety, 28, 417-433. http://dx.doi.org/10.2165/00002018-200528050-00005

[63] Karthaus, M., Ballo, H. and Abenhardt, W. (2005) Prospective, Double Blind, Placebo Controlled, Multicenter, Randomized Phase III Study with Orally Administered Budesonide for Prevention of Irinotecan (CPT-11)-Induced Diarrhea in Patients with Advanced Colorectal Cancer. Oncology, 68, 326-332. http://dx.doi.org/10.1159/000086971

[64] Chowbay, B., Sharma, A., Zhou, Q., Cheung, Y.B. and Lee, E.J.D. (2003) The Modulation of Irinotecan-Induced Diarrhoea and Pharmacokinetics by Three Different Classes of Pharmacological Agents. Oncology Reports, 10, 745-751.

[65] Kehrer, D.F., Sparreboom, A., Verweij, J., De Bruijn, P., Nierop, C.A., Van De Schraaf, J., Ruijgrok, E.J. and De Jonge, M.J. (2001) Modulation of Irinotecan-Induced Diarrhea by Cotreatment with Neomycin in Cancer Patients. Clinical Cancer Research, 7, 1136-1141.

[66] Schmittel, A., Jahnke, K., Theil, E. and Keilholz, U. (2004) Neomycin as a Secondary Prophylaxis for Irinotecan-Induced Diarrhea. Annals of Oncology, 15, 1296. http://dx.doi.org/10.1093/annonc/mdh310

[67] Flieger, D., Klassert, C., Hainke, S., Keller, R., Kleinschmidt, R. and Fischbach, W. (2007) Phase II Clinical Trial for Prevention of Delayed Diarrhea with Cholestyramine/Levofloxacin in the Second-Line Treatment with Irinotecan Biweekly in Patients with Metastatic Colorectal Carcinoma. Oncology, 72, 10-16. http://dx.doi.org/10.1159/000111083

[68] De Jong, F.A., Scott-Horton, T.J., Kroetz, D.J., McLeod, H.L., Friberg, L.E., Mathijssen, R.H., Verweij, J., Marsh, S. and Sparreboom, A. (2007) Irinotecan-Induced Diarrhea: Functional Significance of the Polymorphic ABCC2 Transporter Protein. Clinical Pharmacology and Therapeutics, 81, 42-49. http://dx.doi.org/10.1038/sj.clpt.6100019

[69] Furnam, W.L., Crews, K.R., Billups, C., Wu, J., Gajjar, A.J., Daw, N.C., Patrick, C.C., Rodriguez-Galindo, C., Stewart, C.F., Dome, J.S., Panetta, J.C., Houghton, P.J. and Santana, V.M. (2006) Cefixime Allows Greater Dose Escalation of Oral Irinotecan: A Phase I Study in Pediatric Patients with Refractory Solid Tumours. Journal of Clinical Oncology, 24, 563-570. http://dx.doi.org/10.1200/JCO.2005.03.2847

[70] De Pestel, D.D. and Aronoff, D.M. (2013) Epidemiology of Clostridium difficile Infection. Journal of Pharmacy Prac- 
tices, 26, 464-475. http://dx.doi.org/10.1177/0897190013499521

[71] Khanna, S. and Pardi, D.S. (2012) Clostridium difficile Infection: New Insights into Management. Mayo Clinic Proceedings, 87, 1106-1117. http://dx.doi.org/10.1016/j.mayocp.2012.07.016

[72] Levine, S.A., Nath, S.K., Tse, C.M., Yun, C. and Donowitz, M. (1994) L-Glutamine in Intestinal Sodium Absorption: Lessons for Physiology, Pathobiology and Therapy for Diarrhea. Gastroenterology, 106, 1698-1702.

[73] Fox, A.D., Kripke, S.A., De Paula, J., Berman, J.M., Settle, R.G. and Rombeau, J.L. (1988) Effects of a GlutamineSupplemented Enteral Diet on Methotrexate-Induced Enterocolitis. Journal of Parenteral and Enteral Nutrition, 12, 325-331. http://dx.doi.org/10.1177/0148607188012004325

[74] Xue, H., Sawyer, M.B., Field, C.J., Dieleman, L.A., Murray, D. and Baracos, V.E. (2008) Bolus Oral-Glutamine Protects Rats against CPT-11-Induced Diarrhea and Differentially Activates Cytoprotective Mechanisms in the Host Intestine but Not Tumour. The Journal of Nutrition, 138, 740-746.

[75] Daniele, B., Perrone, F., Gallo, C., Pignata, S., De Martino, S., De Vivo, R., Barlettaa, E., Tambaroa, R., Abbiatie, R. and D’Agostino, L. (2001) Oral Glutamine in the Prevention of Fluorouracil Induced Intestinal Toxicity: A Double Blind, Placebo Controlled, Randomised Trial. Gut, 48, 28-33. http://dx.doi.org/10.1136/gut.48.1.28

[76] Kozelsky, T.F., Meyers, G.E., Sloan, J.A., Shanahan, T.G., Dick, S.J., Moore, R.L., et al. (2003) Phase III DoubleBlind Study of Glutamine versus Placebo for the Prevention of Acute Diarrhea in Patients Receiving Pelvic Radiation Therapy. Journal of Clinical Oncology, 21, 1669-1674. http://dx.doi.org/10.1200/JCO.2003.05.060

[77] Li, Y., Ping, X., Yu, B., Liu, F., Ni, X. and Li, J. (2009) Clinical Trial: Prophylactic Intravenous Alanyl-Glutamine Reduces the Severity of Gastrointestinal Toxicity Induced by Chemotherapy: A Randomized Crossover Trial. Alimentary Pharmacology \& Therapeutics, 30, 452-458. http://dx.doi.org/10.1111/j.1365-2036.2009.04068.x

[78] Sun, J., Wang, H. and Heping, H. (2012) Glutamine for Chemotherapy Induced Diarrhea: A Meta-Analysis. Asia Pacific Journal of Clinical Nutrition, 21, 380-385.

[79] Pytlik, R., Benes, P., Patorkova, M., Chocenska, E., Gregora, E. and Prochazka, B. (2002) Standardized Parenteral Alanyl-Glutamine Dipeptide Supplementation Is Not Beneficial in Autologous Transplant Patients: A Randomized, Double-Blind, Placebo Controlled Study. Bone Marrow Transplantation, 30, 953-961. http://dx.doi.org/10.1038/sj.bmt.1703759

[80] Kornblau, S., Benson III, A.B. and Catalano, R. (2000) Management of Cancer Treatment-Related Diarrhea: Issues and Therapeutic Strategies. Journal of Pain and Symptom Management, 19, 118-129. http://dx.doi.org/10.1016/S0885-3924(99)00149-9

[81] Michael, M., Brittain, M. and Nagai, J. (2004) Phase II Study of Activated Charcoal to Prevent Irinotecan-Induced Diarrhea. Journal of Clinical Oncology, 22, 4410-4417. http://dx.doi.org/10.1200/JCO.2004.11.125

[82] Tack, J.F., Miner, P.B., Fischer, L. and Harris, M.S. (2011) Randomised Clinical Trial: The Safety and Efficacy of AST-120 in Non-Constipating Irritable Bowel Syndrome: A Double Blind, Placebo Controlled Study. Alimentary Pharmacology \& Therapeutics, 34, 868-877. http://dx.doi.org/10.1111/j.1365-2036.2011.04818.X

[83] Maeda, Y., Ohune, T., Nakamyra, M., Yamasaki, M., Kiribayashi, Y. and Murakami, T. (2004) Prevention of IrinotecanInduced Diarrhoea by Oral Carbonaceous Adsorbens (Kremezin) in Cancer Patients. Oncology Reports, 12, 581-585.

[84] Thiagarajah, J.R., Broadbent, T., Hsieh, E. and Verkman, A.S. (2004) Prevention of Toxin-Induced Intestinal Ion and Fluid Secretion by a Small-Molecule CFTR Inhibitor. Gastroenterology, 126, 511-519. http://dx.doi.org/10.1053/j.gastro.2003.11.005

[85] Thiagarajah, J.R. and Verkman, A.S. (2012) CFTR Inhibitors for Treating Diarrheal Disease. Clinical Pharmacology and Therapeutics, 92, 287-290.

[86] Ko, E.A., Jin, B.J., Namkung, W., Ma, T., Thiagarajah, J.R. and Verkman, A.S. (2013) Chloride Channel Inhibition by Red Wine Extract and a Synthetic Small Molecule Prevents Rotaviral Secretory Diarrhoea in Neonatal Mice. Gut, $1-10$.

[87] Camilleri, M. (2008) Novel Pharmacology: Asimadoline, a K-Opioid Agonist, and Visceral Sensation. Neurogastroenterology and Motility, 20, 971-979.

[88] Bender, H.M. and Dasenbrock, J. (1998) Brain Concentration of Asimadoline in Mice: The Influence of Coadministration of Various P-Glycoprotein Substrates. International Journal of Clinical Pharmacology and Therapeutics, 36, 76-79.

[89] Mangel, A.W. and Hicks, G.A. (2012) Asimadoline and Its Potential for the Treatment of Diarrhea-Predominant Irritable Bowel Syndrome: A Review. Clinical and Experimental Gastroenterology, 5, 1-10. http://dx.doi.org/10.2147/CEG.S23274

[90] Mangel, A.W., Bornstein, J.D., Hamm, L.R., Buda, J., Wang, J., Irish, W. and Urso, D. (2008) Clinical Trial: Asimadoline in the Treatment of Patients with Irritable Bowel Syndrome. Alimentary Pharmacology \& Therapeutics, 28, 239249. http://dx.doi.org/10.1111/j.1365-2036.2008.03730.x 
[91] Turck, D., Berard, H. and Fretault, N. (1999) Comparison of Racecadotril and Loperamide in Children with Acute Diarrhoea. Alimentary Pharmacology \& Therapeutics, 13, 27-32. http://dx.doi.org/10.1046/j.1365-2036.1999.00004.x-i1

[92] Cezard, J.P., Duhamel, J.F. and Meyer, M. (2001) Efficacy and Tolerability of Racecadotril in Acute Diarrhea in Children. Gastroenterology, 120, 799-805. http://dx.doi.org/10.1053/gast.2001.22544

[93] Baumer, P., Danquechin, D.E. and Bertrand, J. (1992) Effects of Acetorphan, an Enkephalinase Inhibitor, on Experimental and Acute Diarrhoea. Gut, 33, 753-758. http://dx.doi.org/10.1136/gut.33.6.753

[94] Cezard, J.P., Duhamel, J.F. and Meyer, M. (1996) Efficacy and Tolerance of Acetorphan in Infant Actute Diarrhea. A Multicentric Double Blind Study. Gastroenterology, 110, A795.

[95] Roge, J., Baumer, P. and Berard, H. (1993) The Enkephalinase Inhibitor Acetorphan, in Acute Diarrhoea. A DoubleBlind, Controlled Clinical Trial versus Loperamide. Scandinavian Journal of Gastroenterology, 28, 352-354.

[96] Vetel, J.M., Berard, H. and Frerault, N. (1995) Comparison of Racecadotril and Loperamide in Adults with Acute Diarhhoea. Alimentary Pharmacology \& Therapeutics, 13, 21-26. http://dx.doi.org/10.1046/j.1365-2036.1999.00003.x-i1

[97] Matheson, A.J. and Noble, S. (2000) Racecadotril. Drugs, 59, 829-835. http://dx.doi.org/10.2165/00003495-200059040-00010

[98] Esfandyari, T., Camilleri, M., Ferber, I., Burton, D., Baxter, K. and Zinsmeister, A.R. (2006) Effect of a Cannabinoid Agonist on Gastrointestinal Transit and Postprandial Satiation in Healthy Human Subjects: A Randomized, PlaceboControlled Study. Neurogastroenterology \& Motility, 18, 831-838. http://dx.doi.org/10.1111/j.1365-2982.2006.00834.x

[99] Esfandyari, T., Camilleri, M., Busciglio, I., Burton, D., Baxter, K. and Zinsmeister, A.R. (2007) Effects of a Cannabinoid Receptor Agonist on Colonic Motor and Sensory Functions in Humans: A Randomized, Placebo-Controlled Study. American Journal of Physiology. Gastrointestinal and Liver Physiology, 293, G137-G145.

[100] Wong, B., Camilleri, M., Busciglio, I., Carlson, P., Szarka, L.A., Burton, D. and Zinsmeister, A.R. (2011) Pharmacogenetic Trial of a Cannabinoid Agonist Shows Reduced Fasting Colonic Motility in Patients with Nonconstipated Irritable Bowel Syndrome. Gastroenterology, 141, 1638-1647. http://dx.doi.org/10.1053/j.gastro.2011.07.036

\section{Abbreviations}

\section{5-FU: 5-Fluorouracil}

CAPEOX: Combination of Capecitabine and Oxaliplatin. Also known as XELOX.

CID: Chemotherapy-Induced Diarrhoea

CRC: Colorectal Cancer

DTO: Deodorized Tincture of Opium

FOLFIRI: Combination of 5-Fluorouracil, Irinotecan and Leucovorin.

FOLFOX: Combination of 5-Fluorouracil, Oxaliplatin and Leucovorin.

FOLFOXIRI: Combination of 5-Fluorouracil, Oxaliplatin, Irinotecan and Leucovorin

HIV: Human Immunodeficiency Virus

IBS: Irritable Bowel Syndrome

NCI: National Cancer Institute

XELOX: Combination of Capecitabine and Oxaliplatin. Also known as CAPEOX. 